\title{
Angiotropic large cell lymphoma with mononeuritis multiplex mimicking systemic vasculitis
}

\author{
S Roux, M Grossin, M De Bandt, E Palazzo, F Vachon, M F Kahn
}

\begin{abstract}
Angiotropic large cell lymphoma (ALCL), the socalled malignant angioendotheliomatosis, is characterised by proliferation of tumorous cells within small vessels. Manifestations in the CNS and cutaneous lesions prevail in the clinical presentation, although any organ can be involved. The recent classification of this lymphoma as part of the large cell lymphomas has modified the therapeutic approaches employed. This should improve the prognosis of this usually fatal disease. An unusual case presenting with fever, mononeuritis multiplex, and cutaneous lesions is reported. Peripheral neuropathy without other neurological symptoms is uncommon, and, to our knowledge, such isolated mononeuritis multiplex with nerve lesions has not been previously reported in ALCL. The clinical diagnosis was a systemic necrotising vasculitis and it is considered that its differential diagnosis must include angiotropic large cell lymphoma.
\end{abstract}

(F Neurol Neurosurg Psychiatry 1995;58:363-366)

Keywords: angiotropic large cell lymphoma; malignant angioendotheliomatosis; mononeuritis multiplex

Bichat Hospital, 46, rue Henri-Huchard, F 75778 Paris Cedex 18, France

Department of

Rheumatology

S Roux

$M$ De Bandt

E Palazzo

M F Kahn

Department of

Pathology

M Grossin

Department of

Infectious diseases

F Vachon

Correspondence to:

Dr $\mathrm{S}$ Roux, Inserm unité

349, Centre Viggo Petersen,

Hôpital Lariboisière, 6 , rue

Guy Patin, 75010 Paris,

France.

Received 12 September 1994

and in revised form

October 1994.

Accepted 27 October 1994
Malignant angioendotheliomatosis is a rare, generally fatal neoplasm. It was first described by Pfleger and Tappeiner in 1959 as "angioendotheliomatosis proliferans systemisata"." Angioendotheliomatosis was subsequently divided into two distinct categories. ${ }^{2}$ The "reactive angioendotheliomatosis" represents a peculiar form of cutaneous vasculitis that is a benign endothelial proliferation. "Malignant angioendotheliomatosis" is characterised by proliferation of tumour cells within small vessels throughout the body, especially in the brain and skin. In the past decade, immunohistochemical studies have clearly shown the lymphoid nature of the large malignant proliferating cells. Hence, the term "angiotropic large cell lymphoma" was proposed to avoid confusion with reactive angioendotheliomatosis. ${ }^{3}$

We report a new case of angiotropic large cell lymphoma (ALCL). The clinical presentation was a prevalent peripheral neuropathy, associated with signs and symptoms suggesting a systemic necrotising vasculitis, such as polyarteritis nodosa.

\section{Case report}

A 77 year old man was admitted for asthenia, weight loss, and fever $\left(38.5^{\circ} \mathrm{C}\right)$, that had been present for two months before admission. Medical history included arterial hypertension and serous otitis media treated by myringotomy tube three years previously. One month before admission, skin lesions had been noticed on the left arm, forearm, and leg, then subsequently on the lower part of the abdomen and on the thighs. The lesions were successive and regressive within seven to 10 days. They appeared as inflammatory, infiltrated, and irregularly limited plaques a few $\mathrm{cm}$ in diameter. One of these was strongly suggestive of livedo reticularis. Initially, inflammatory arthralgias and myalgias were present. The patient then developed asymmetric sensorimotor neuropathy of the legs, involving initially the popliteal nerves, which progressively worsened. At the time of admission he also complained of bilateral testicular pain with local inflammation; this regressed within a few days.

Routine haematological and immunological studies showed no abnormalities, except for lactate dehydrogenase, which was raised to 700 to $1000 \mathrm{IU} / \mathrm{ml}$. Electromyography and nerve conduction studies of the legs showed an axonal sensorimotor neuropathy. The CSF was normal. Abdominothoracic CT and medullary MRI were normal. Histological examination of a skin biopsy showed a leucocytoclastic vasculitis; a muscle biopsy, a myelogram, and a bone marrow biopsy were normal.

The neurological manifestations in the legs progressively worsened, and four months after the initial symptoms, neurological examination disclosed flaccid paraplegia, severe hypoaesthesia, perineal anaesthesia, urinary retention, and anal incontinence. His knee and ankle reflexes disappeared. He developed massive oedema with subsequent hypotension and profound hyponatraemia. Progressively, a central hypothyroidism occurred; triiodothyronine, thyroxine and $\mathrm{TSH}$ concentrations were very low, and FSH and LH concentra- 
tions were also low. Concentrations of ACTH and prolactin were normal. Repeated abdominal ultrasound showed splenic nodules, without adenopathy or other abnormality. Repeated abdominothoracic CT and cerebral and medullary MRI were normal. Finally, the patient developed a bilateral otitis media.

A systemic necrotising vasculitis of the polyarteritis nodosa group was considered the most likely diagnosis. Therefore, the patient was treated with steroids and monthly pulses of cyclophosphamide, as well as thyroxine. Nevertheless he deteriorated and became bedridden; he died six months after the onset of symptoms. A necropsy was performed.

\section{NECROPSY FINDINGS}

The spleen was enlarged and multinodular without any sign of adenopathy. Histologically, spleen parenchyma seemed completely disrupted by many atypical

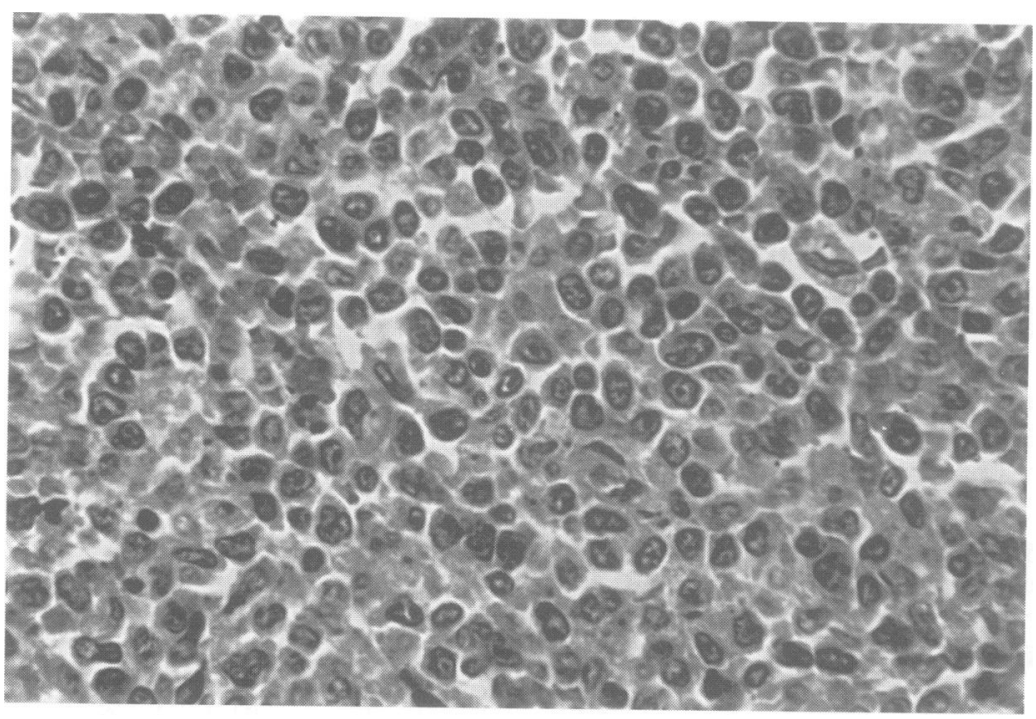

Figure 1 Section of spleen parenchyma stained by haematein-phloxin-saffrinin (originally $\times 40$ ) showing large cell splenic lymphoma.

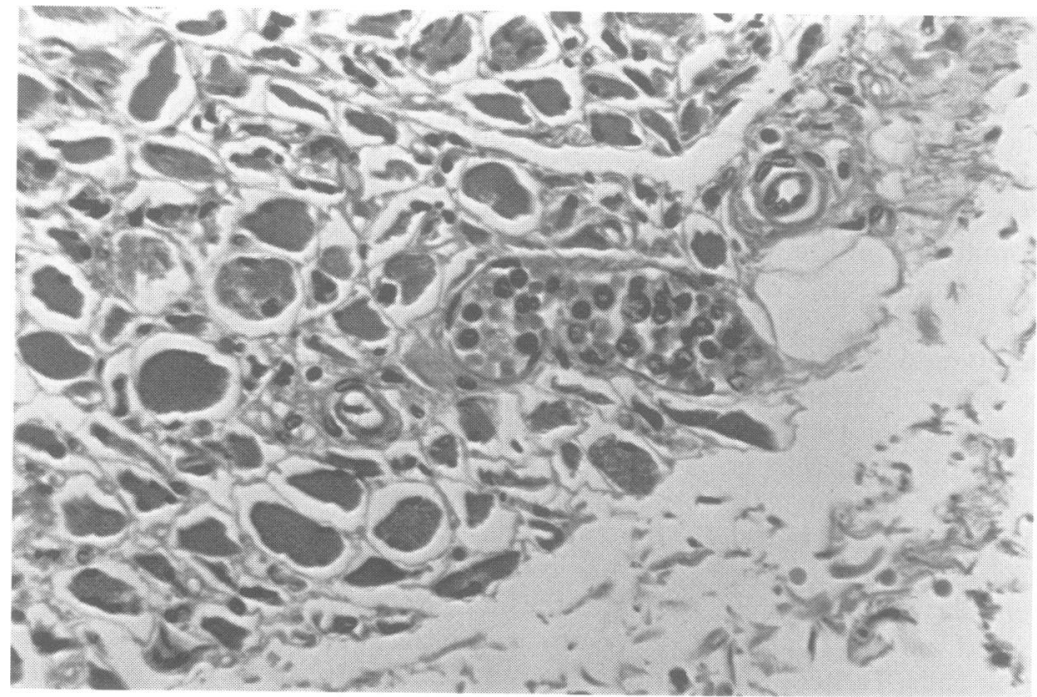

Figure 2 Section of skeletal muscle stained by haematein-phloxin-saffrinin (originally $\times$ 25) showing angiotropic large cell lymphoma involving muscle: skeletal muscle fibres are atrophic and malignant intraluminal cells are present in a perimysial capillary (transverse
section). pleomorphic cells, corresponding to lymphoid large cells; thus it was a splenic large cell lymphoma (fig 1). The nodular splenic proliferation and the morphology of the cells were strongly suggestive of a B cell lineage lymphoma, although the immunohistological findings did not enable us to reach a definite conclusion. Immunohistochemical staining with B cell markers (L26, antilambda and antikappa antibodies) and $T$ cell markers (UCHL1) were negative; this may have been due either to tissue postmortem autolytic alteration or to lack of expression of these antigens by the lymphomatous cells.

As well as the splenic lesions, the microscopic findings showed generalised, intravascular proliferation of the same malignant cells. In several organs many small blood vessels were filled with (and sometimes occluded by) neoplastic cells; this was seen in the kidneys, liver, bladder, lungs, and muscle (fig 2). The lymphomatous proliferation was particularly evident in perineural capillaries of peripheral nerves. Bone marrow, lymph nodes, pancreas and brain seemed uninvolved. There was a massive hypophyseal involution. There were no vasculitic lesions in the organs involved.

\section{Discussion}

On the basis of mononeuritis multiplex, cutaneous lesions, fever, weight loss, fatigue, arthralgiae, and myalgiae, a clinical diagnosis of systemic necrotising vasculitis such as polyarteritis nodosa was considered. The association of polyarteritis nodosa with leucocytoclastic vasculitis involving small vessels is well known. ${ }^{4}$ Evidence of testicular symptoms ${ }^{5}$ and serous otitis media ${ }^{6}$ would argue in favour of such a diagnosis. The presence of partial hypopituitarism could be explained by local vasculitis. ${ }^{7}$ There was no histological evidence, however, of necrotising vasculitis involving medium size vessels. Furthermore, the splenic nodules and the increased lactate dehydrogenase concentrations were not explained by this diagnosis. The necropsy findings led us to the diagnosis of angiotropic (intravascular) large cell lymphoma associated with splenic lymphoma, which was probably a centroblastic polymorphous B cell type lymphoma.

The disease ALCL is a systemic neoplasm characterised by proliferation of large atypical lymphoid cells within small blood vessels. This diffuse, multifocal process results in obstruction of the lumen of the involved vessels. Immunohistochemical studies have shown leucocyte common antigen and lymphoid marker expression on malignant cells. These large lymphomatous cells are most often of B cell lineage, less commonly of $\mathrm{T}$ cell lineage. ${ }^{8}$

In clinical presentation of ALCL, constitutional symptoms are common. Neurological manifestations are present in almost two thirds of patients; these usually include progressive, multifocal cerebrovascular events, subacute encephalopathy, and spinal cord 
and nerve root vascular syndromes. Cranial neuropathies have been occasionally reported, as have peripheral neuropathies. These different syndromes are often overlapping, and seizures can also occur. ${ }^{8}$ Cutaneous manifestations are seen in about one third of patients. These are non-specific and include erythematous, indurated plaques and nodules. Telangiectasia may be prominent on the skin lesions. ${ }^{910}$ Most often ALCL presents either with central neurological signs and symptoms or with cutaneous lesions, although any organ can be involved. In some cases, massive oedema and anasarca have been reported, as in this patient. These symptoms can be explained by an alteration of capillary permeability due to diffuse small vessel occlusion. Laboratory investigations commonly show anaemia, increased erythrocyte sedimentation rate, and increased lactate dehydrogenase. Atypical cells are occasionally found in peripheral blood smears or spinal fluid.

Hypopituitarism was diagnosed clinically and the massive involution of the hypophyseal gland was probably due to vascular occlusion with infarcts or ischaemic necrosis; such a phenomenon has been previously described. ${ }^{11}$ A leucocytoclastic vasculitis was present. Paraneoplastic cutaneous vasculitis, including leucocytoclastic ${ }^{12}$ and lymphocytic vasculitis, ${ }^{13}$ have been previously reported in ALCL.

Our patient presented with mononeuritis multiplex, secondary to vasa nervorum involvement, without other neurological symptoms. Such isolated peripheral neuropathy with nerve lesions is very unusual, and to our knowledge, it has been reported only twice, as acute mononeuropathy ${ }^{14}$ and Guillain-Barré syndrome. ${ }^{11}$

The diagnostic procedure for cases of ALCL includes biopsy of the involved organ. Nevertheless, in most cases the diagnosis is made at necropsy. Considering the clinical picture, it is surprising that necropsy shows a multisystemic involvement in $90 \%$ of patients. ${ }^{15}$ Virtually any organ can be affected. Brain, spinal cord, and skin, but also kidneys, lungs, adrenals, liver are generally involved. On the other hand, haematopoietic tissues are usually spared. This surprising fact could be explained by an altered expression in lymphocyte homing receptors that could cause lymphomatous cells to be retained within small vessels, without migration towards lymphoid tissues through high endothelial venules. ${ }^{16}$

Lymphomatous mass lesions as well as intravascular lymphoma have been seen occasionally, as was the case in our patient presenting with splenic lymphoma. These large cell non-angiotropic lymphoma locations were diagnosed simultaneously, but sometimes precede ALCL. ${ }^{817}$

The disease is usually rapidly fatal, with a high mortality and a median survival of five months. ${ }^{15}$ Nevertheless in some cases, patients treated with combination chemotherapy were reported to have achieved clinical remission. Although these patients mostly had limited cutaneous forms, ${ }^{910} 18$ remission has also been obtained in neurological forms, ${ }^{19-21}$ in renal forms, ${ }^{22}$ and in pulmonary forms. ${ }^{23} 24$ The recent classification of ALCL among large cell lymphomas has modified the therapeutic approaches employed, and it is expected that, as in the non-vascular large cell lymphomas, polychemotherapy protocols would improve prognosis in future.

Small vessels are involved in ALCL, and tissues can be damaged by ischaemia due to the lumen becoming occluded by lymphomatous cells. Thus richly vascularised organs are usually involved, such as the brain, skin, and kidney. In vasculitides, systemic lesions are caused by an ischaemic mechanism, which could explain the clinical similarities between these two diseases. A patient has previously been described as presenting with recurrent neurological events, skin lesions, renal insufficiency, pulmonary involvement and fever, an association of symptoms that mimics systemic necrotising vasculitis. ${ }^{25}$ In our patient, a mononeuritis multiplex associated with multisystemic involvement was also strongly suggestive of systemic vasculitis. In accord with Kao et al, ${ }^{25}$ we conclude that differential diagnosis of systemic necrotising vasculitis must include ALCL.

1 Pfleger L, Tappeiner J. Zur Kenntnis der systemisierten endotheliomastose der cutanen blutgefasse (reticuloendotheliose?). Hautarzt 1959;10:359-63. (In german.)

2 Wick MR, Rocamora A. Reactive and malignant "angioendotheliomatosis": a discriminant clinicopathological study. F Cutan Pathol 1988;15:260-71.

3 Wrotnowski U, Mills SE, Cooper PH. Malignant angioendotheliomatosis: an angiotropic lymphoma? Am $\mathcal{f}$ Clin Pathol 1985;83:244-8.

4 Leavitt RY, Fauci AS. Polyangiitis overlap syndrome. Classification and prospective clinical experience. $A m \mathcal{F}$ Med 1986;81:79-85.

5 Shurbaji MS, Epstein JI. Testicular vasculitis: implications for systemic disease. Hum Pathol 1988;19:186-9.

6 Sergent JS, Christian CL. Necrotizing vasculitis after acute serous otitis media. Ann Intern Med 1974;81: 195-9.

7 Miller RH, Chen JJS, Ney RL, Tumulty P. Granulomatous angiitis presenting with polymyalgia rheumatica and abnormal pituitary function. Ann Intern Med 1985;102:210-1.

8 Glass J, Hochberg FH, Miller DC. Intravascular lymphomatosis. A systemic disease with neurologic manifes-

tations. Cancer 1993;73:3156-64.
9 Wilson BB. Indurated telangiectatic plaques. Malignant angioendotheliomatosis (MAE). Arch Dermatol 1992; 128:255-8.

10 Chakravarty K, Goyal M, Scott DGI, McCann BG. Malignant "angioendotheliomatosis" (intravascular lymphomatosis): an unusual cutaneous lymphoma in rheumatoid arthritis. $B r f$ Rheumatol 1993;32: 932-4.

11 Dolman CL, Sweeney VP, Magil A. Neoplastic angioendotheliosis: the case of the missed primary? Arch Neurol 1979;36:5-7.

12 Al-Hazzaa SA, Green WR, Mann RB. Uveal involvement in systemic angiotropic large cell lymphoma: microin systemic angiotropic large cell lymphoma: micro-
scopic and immunohistochemical studies. Ophtalmology
1993;100:961-5.

13 Drobacheff C, Blanc D, Zultak M, et al. Malignant angioendotheliomatosis: reclassification as an angiotropic ymphoma. Int f Dermatol 1989;28:454-6.

14 Vital C, Heraud A, Vital A, et al. Acute mononeuropathy with angiotropic lymphoma. Acta Neuropathol (Berl) 1989;78:105-7.

15 Domizio P, Hall PA, Cotter F, et al. Angiotropic large cell lymphoma (ALCL): morphological, immunohistochemical and genotypic studies with analysis of previous report. Hematol Oncol 1989;7:195-206.

16 Setoyama M, Mizoguchi S, Orikawa T, Tashiro M. A case of intravascular malignant lymphomatosis (angiotropic large-cell lymphoma) presenting memory $\mathrm{T}$ cell phenotype and its expression of adhesion molecules. $f$ Dermatol 1992;19:263-9.

17 Lopez-Gil F, Roura M, Umbert I, Umbert P. Malignant proliferative angioendotheliomatosis or angiotropic lymphoma associated with a soft-tissue lymphoma. If $\mathrm{Am}$ Acad Dermatol 1992;26:101-4. 
18 Williams DB, Lyons MK, Yanagihara $T$, Colgan JP, Banks PM. Cerebral angiotropic large cell lymphoma Banks PM. Cerebral angiotropic large cell lymphoma (neoplastic angioendotheliosis): the

$19 \mathrm{Lim} \mathrm{HW}$, Anderson HM. Angioendotheliomatosis associated with histiocytic lymphoma: response to systemic ated with histiocytic lymphoma: response to syste
chemotherapy. $₹ \mathrm{Am}$ Acad Dermatol 1985;13:903-8.

20 Axelsen RA, Laird PP, Horn M. Intravascular large cell lymphoma: diagnosis on renal biopsy. Pathology 1991; 23:241-3

21 Petroff N, Koger OW, Fleming MG, et al. Malignant angioendotheliomatosis: an angiotropic lymphoma. $f$ Am Acad Dermatol 1989;21:727-33.
22 Nishikawa K, Sekiyama S, Suzuki T, et al. A case of angiotropic large cell lymphoma manifesting nephrotic syndrome and treated successfully with combination chemotherapy. Nephron 1991;58:479-82.

23 Yousem SA, Colby TV. Intravascular lymphomatosis presenting in the lung. Cancer 1990;65:349-53.

24 Stroup RM, Sheibani K, Moncada A, Purdy LJ, Battifora H. Angiotropic (intravascular) large cell lymphoma. A clinicopathologic study of seven cases with unique clinical presentations. Cancer 1990;66:1781-8.

25 Kao NL, Broy S, Tillawi I. Malignant angioendotheliomatosis mimicking systemic necrotizing vasculitis. $f$ Rheumatol 1992;19:1133-5.

\section{NEUROLOGY IN LITERATURE}

\section{Visual disorders}

With the exception of the physiological observations of Norman Douglas and Edgar Allan Poe (of which Poe more impresses), the extracts I have chosen principally refer to vascular disorders affecting vision. Charlotte Brontë's father presumably suffered an episode of occipital ischaemia, probably related to transient occlusion of the terminal basilar artery. A similar process probably affected Nero. The accounts by Wilkie Collins and Thomas Hardy are intriguing. The subject of Collins' description is in his 20s. Prodromal pain does not exclude a diagnosis of Leber's optic atrophy although it would usually be distributed frontally or in the orbital region. Hardy seems to suggest that Yeobright's ocular pain is photophobic and it is perhaps more likely that he is describing an acute iritis than optic neuritis. If the latter had been the case, Hardy would have antedated the descriptions of Nettleship, Parinaud, Uhthoff, Buzzard, and Marcus Gunn!

Edgar Allan Poe, 1841, Tales of mystery and imagination. The murders in the Rue Morgue

To look at a star by glances-to view it in a side-long way by turning towards it the exterior portions of the retina (more susceptible of feeble impression of light than the interior) is to behold the star distinctly-is to have the best appreciation of its lustre-a lustre which grows dim just in proportion as we turn our vision fully upon it. A greater number of rays actually fall upon the eye in the latter case, but, in the former, there is the more refined capacity for comprehension.

Elizabeth Gaskell, 1857, The life of Charlotte Brontë My dear father has borne the severe winter very well, a circumstance for which I feel the more thankful as he had many weeks of very precarious health last summer, following an attack from which he suffered in June, and which for a few hours deprived him totally of sight, though neither his mind, speech nor even his powers of motion were in the least affected. I can hardly tell you how thankful I was, when, after that dreary and almost despairing interval of utter darkness, some gleam of daylight became visible to him once more. I had feared that paralysis had seized the optic nerve. A sort of mist remained for a long time; and, indeed, his vision is not yet perfectly clear, but he can read, write, and walk about. . .

Wilkie Collins, 1857, The dead secret About the last work he did, poor fellow, was the repairing of my watch-here it is; goes as regular as a steam-engine. I hadn't got it back into my fob very long before I heard that he was getting a bad pain at the back of his head, and that he saw all sorts of moving spots before his eyes. String him up with lots of port wine, and give him three hours a day on the back of a quiet pony-that was my advice. Instead of trying it, they sent for doctors from London, and blistered him behind the ears and between the shoulders, and drenched the lad with mercury, and moped him up in a dark room. No use. The sight got worse and worse, flickered and flickered, and went out at last like the flame of a candle. . . His father was half out of his mind. Took him to oculists in London, and oculists in Paris. All they did was to call the blindness by a long Latin name, and to say that it was hopeless and useless to try an operation. Some of them said it was the result of the long weakness from which he had twice suffered after illness. Some said it was an apoplectic effusion in the brain. . . . So they brought him back home, blind, blind he is now; and blind he will remain, poor fellow, for the rest of his life.

Thomas Hardy, 1878, The return of the native One morning, after a severer strain than usual, he awoke with a strange sensation in his eyes. The sun was shining directly upon the window-blind, and at his first glance thither-ward a sharp pain obliged him to close his eyelids quickly. At every new attempt to look about him the same morbid sensibility to light was manifested, and excoriating tears ran down his cheeks. He was obliged to tie a bandage over his brow while dressing; and during the day it could not be abandoned

... Towards evening he arrived, and pronounced the disease to be an acute inflammation induced by Clym's night studies, continued in spite of a cold previously caught, which had weakened his eyes for the time.

. He was not to be blind: that was enough. To be doomed to behold the world through smoked glass for an indefinite period was bad enough, and fatal to any kind of advance.

Amold Bennett, 1906, Whom God hath joined

"When I woke up the next morning in the hotel, I couldn't make out what was the matter with me. Something with my left eye-I couldn't see out of it, and I was so feeble, I just managed to get as far as a doctor's. The doctor said I'd had a haemorrhage into my retina while I was asleep."

Continued on page 370 